\title{
Preservação digital: estudo exploratório sobre a literatura científica e as redes sociais colaborativas no Brasil
}

\author{
Digital preservation: exploratory study on scientific literature and \\ collaborative social networks in Brazil
}

\section{Preservación digital: estudio exploratorio sobre literatura científica y redes sociales colaborativas en Brasil}

\author{
Aureliana Lopes de Lacerda Tavares ${ }^{1, a}$ \\ lianapb@gmail.com | http://orcid.org/o0oo-0002-1434-8089 \\ Isa Maria Freire ${ }^{1, b}$ \\ isafreire@globo.com | http://orcid.org/o00o-0001-7603-1872
}

${ }^{1}$ Universidade Federal da Paraíba, Programa de Pós-Graduação em Ciência da Informação, João Pessoa, PB, Brasil.

aMestrado em Ciência da Informação pela Universidade Federal de Pernambuco.

bDoutorado em Ciência da Informação pela Universidade Federal do Rio de Janeiro.

\section{RESUMO}

Apresenta um mapeamento realizado na Base de Dados em Ciência da Informação sobre preservação digital, objetivando identificar autores, instituições e periódicos científicos que disseminaram essa temática no Brasil entre 2000 e 2019. Toma como base um estudo exploratório e descritivo com abordagem qualiquantitativa dos dados analisados. Utiliza a metodologia de Análise de Redes Sociais para caracterizar as relações das redes de coautorias que se estabelecem via produção científica sobre o tema em questão. O corpus final foi constituído por 61 artigos que apontam para um crescente interesse nas publicações sobre o tema na Ciência da Informação, ainda destaca 24 periódicos científicos que divulgaram essas pesquisas e 25 instituições onde se concentram os pesquisadores da área. Na análise de redes, destaca a colaboração científica como prática na produção do conhecimento divulgado, muito embora essa rede seja formada por sub-redes - o que a caracteriza como fragmentada e de baixa densidade.

Palavras-chave: Preservação digital; Comunicação científica; Redes sociais; Colaboração científica; Ciência da Informação. 


\section{ABSTRACT}

Presents a mapping carried out in the Information Science Database on digital preservation, aiming to identify the authors, institutions and scientific journals that disseminated this theme in Brazil between 2000 and 2019. It is based on an exploratory and descriptive study with a qualitative and quantitative approach of analyzed data. It uses the Social Network Analysis methodology to characterize the relationships of the co-authoring networks that are established via scientific production on the subject in question. The final corpus was made up of 61 articles, which point to a growing interest in publications on the subject in Information Science, highlighting 24 scientific journals that published these researches and 25 institutions where researchers in the area are concentrated. In the analysis of networks, scientific collaboration is highlighted as a practice in the production of disseminated knowledge, although this network is formed by subnets, which characterizes it as fragmented and of low density.

Keywords: Digital preservation; Scientific communication; Social networks; Scientific collaboration; Information Science.

\section{RESUMEN}

Presenta un mapeo realizado en la Base de Datos de Ciencia de la Información sobre preservación digital, con el objetivo de identificar a los autores, instituciones y revistas científicas que difundieron este tema en Brasil entre 2000 y 2019. Se basa en un estudio exploratorio y descriptivo con un enfoque cualitativo y cuantitativo de datos analizados Utiliza la metodología de Análisis de Redes Sociales para caracterizar las relaciones de las redes de coautoría que se establecen a través de la producción científica sobre el tema en cuestión. El corpus final consistió en 61 artículos, que apuntan a un creciente interés en publicaciones sobre el tema en Ciencias de la Información, aún destacando 24 revistas científicas que diseminaron estas investigaciones y 25 instituciones donde se concentran los investigadores en el área. En el análisis de redes, la colaboración científica se destaca como una práctica en la producción de conocimiento diseminado, aunque esta red está formada por subredes, que la caracterizan como fragmentada y de baja densidad.

Palabras clave: Preservación digital; Comunicación científica; Redes sociales; Colaboración científica; Ciencias de la información.

Este artigo compõe o Dossiê Preservação Digital.

Contribuição dos autores:

Concepção e desenho do estudo: Isa Maria Freire.

Aquisição, análise ou interpretação dos dados: Aureliana Lopes de Lacerda Tavares.

Redação do manuscrito: Aureliana Lopes de Lacerda Tavares, Isa Maria Freire.

Revisão crítica do conteúdo intelectual: Isa Maria Freire; Aureliana Lopes de Lacerda Tavares.

Declaração de conflito de interesses: não há.

Fontes de financiamento: não houve.

Considerações éticas: não há.

Agradecimentos/Contribuições adicionais: não há.

Histórico do artigo: submetido: 17 maio 2020 | aceito: 19 ago. 2020 | publicado: 30 set. 2020.

Apresentação anterior: não há.

Licença CC BY-NC atribuição não comercial. Com essa licença é permitido acessar, baixar (download), copiar, imprimir, compartilhar, reutilizar e distribuir os artigos, desde que para uso não comercial e com a citação da fonte, conferindo os devidos créditos de autoria e menção à Reciis. Nesses casos, nenhuma permissão é necessária por parte dos autores ou dos editores. 


\section{INTRODUÇÃO}

O uso intensivo de Tecnologias Digitais de Informação e Comunicação (TDIC) trouxe à tona um conjunto de problemas e desafios lançado às instituições de guarda e preservação de acervos memorialísticos, que tiveram que se adaptar, buscando respostas às questões impulsionadas por esses problemas. Um dos problemas mais relevantes envolve questões relacionadas à preservação dos objetos digitais que, fragilizados pelos fatores de risco que os circundam, tornam-se vulneráveis à perda em um curto espaço de tempo. Nesse sentido, a preservação digital visa conceber ações ou medidas para proteger, cuidar e manter os documentos e objetos digitais em condições de serem acessados e reutilizados, assegurando sua autenticidade e integridade ao longo do tempo.

Na Ciência da Informação, a preservação digital já vem sendo difundida há bastante tempo. No cenário internacional, de acordo com Thomaz', as questões relacionadas à preservação da informação digital surgiram na década de 1960, na comunidade arquivística, com a publicação de um relatório sobre os desafios dos documentos eletrônicos para os arquivos no International Congress Council on Archives, em Paris. Mas foi só na década seguinte, segundo a autora, que essas discussões tomaram fôlego devido ao crescimento do uso dos computadores nos arquivos.

No Brasil, foi só a partir de 1990 que começaram a surgir as primeiras publicações sobre Tecnologia da Informação e documentos eletrônicos na área. E, apenas no ano de 2000, pode-se perceber publicações que abordavam uma conscientização da comunidade científica com relação ao tema preservação digital ${ }^{1}$. Desde então, as publicações sobre a temática se multiplicaram e iniciativas foram apresentadas por profissionais, pesquisadores e instituições - como bibliotecas e arquivos -, que necessitavam de estratégias metodológicas bem-definidas para lidar com esses novos problemas.

Destarte, deve-se ressaltar que nesse mesmo contexto histórico a Ciência da Informação se consolidou enquanto campo de conhecimento, utilizando-se dos novos artefatos e dispositivos tecnológicos para lidar com os problemas da recuperação da informação, impulsionando, nesse processo, a Biblioteconomia e a Arquivologia no uso dessas tecnologias para superar os meios tradicionais de preservação e oferecer novas bases para as práticas de gestão e preservação dos documentos digitais.

Nessa perspectiva, destaca-se não somente a produção, mas, especialmente, a comunicação científica, pois é através desse processo que o conhecimento produzido é difundido e democratizado para a sociedade, como forma de compartilhar resultados e dialogar na busca de soluções ou alternativas para problemas de pesquisa. Esse processo comunicativo, também envolve a colaboração científica, que se constitui em um conjunto de estratégias e práticas construídas e vivenciadas pela comunidade científica, que alimentam uma rede de produção e disseminação desse conhecimento para outros pesquisadores.

Dessa forma, analisar a literatura derivada da produção científica de uma temática específica contribui para a compreensão de como uma área de um campo científico vem se desenvolvendo, como também para o entendimento da dinâmica da ciência no âmbito dessa temática Assim, tem-se que essa rede de colaboração científica, que aqui denominamos rede social, fortalece o corpo teórico sobre preservação digital, que ao longo de quase 20 anos de produção científica vem se consolidando no campo da Ciência da Informação, no Brasil. Para Silva² ${ }^{2}$ a produção científica analisa a qualidade e a quantidade das publicações científicas, sendo essas as duas medidas que dão validade a essas produções.

Em sua conjuntura, as redes sociais apresentam quadros de relações capazes de revelar o dinamismo e as interações existentes entre autores, instituições e temáticas abordadas, entre outras variáveis, sendo possível "medir, estimar tendências, lideranças e carências, e também visualizar diferentes aspectos da ciência" (p.119), como reconhecem Leta e Canchumani ${ }^{3}$. Assim, a produção científica compartilhada pela literatura, como parte do processo de comunicação científica, torna-se a base para as análises dessas redes colaborativas, 
através do estudo das coautorias (compartilhamento de autoria). E a Análise de Redes Sociais certamente é a metodologia que melhor representa as relações existentes entre os atores da rede.

Nesse sentido, no presente exercício, pretende-se mapear a literatura científica sobre preservação digital no Brasil, na busca por autores, instituições e periódicos científicos que estão vinculados a essa temática, bem como identificar as redes de colaboração que configuram as relações de coautoria e as ligações que se estabelecem, via produção científica, sobre uma temática específica. Para tanto, buscamos indícios dessa abordagem na Base de Dados em Ciência da Informação (BRAPCI) nas publicações divulgadas entre 2000 e 2019.

\section{CONTEXTO}

Nesta seção é apresentado o quadro conceitual, no qual se fundamenta o presente exercício, iniciado com a abordagem da temática da preservação digital, no campo científico da informação, à qual se segue a abordagem das redes sociais como mapas para identificar a colaboração entre pesquisadores, nos processos de produção e comunicação científica.

\section{Ciência da Informação: diálogos com a preservação digital}

A revolução técnico-científica, ocasionada pelo grande volume de informação acumulado logo após a Segunda Guerra Mundial, demandou um novo modelo de organização informacional que originou a Ciência da Informação. Para Saracevic ${ }^{4}$ foram as questões provocadas pelos problemas que envolviam a recuperação da informação nesse período, que desencadearam a busca da construção de um arcabouço teórico, empírico e prático para essa ciência.

Ao longo dos anos, a Ciência da Informação foi impulsionada por transformações, em decorrência dos avanços científicos e tecnológicos que alteraram radicalmente o seu objeto de estudo: a informação. Registrada por séculos no papel e noutros suportes, essa informação tem, atualmente, seu 'suporte' na tecnologia digital, que não mais a fixa, mas a transporta "transpondo barreiras de tempo e espaço e ampliando sua capacidade de transmissão" (p. 173), como sublinha Barreto ${ }^{5}$.

A informação digital, fixada nesse 'novo suporte', carrega consigo fragilidades, que lhes são conferidas pelos riscos e pelas vulnerabilidades inerentes a esse ambiente de pluridimensionalidades. Assim, a preservação digital é vista como promotora do acesso a longo prazo, sendo uma necessidade para instituições de memória, de pesquisa e para organizações em geral. Nessa conformidade, Innarelli' ${ }^{6}$ diz que "essa nova forma de registro [...], o digital, ao mesmo tempo em que renova as profissões relacionadas à Ciência da Informação, traz novos desafios e com certeza um deles é a preservação dos documentos digitais” (p. 75).

De acordo com Borba7 ${ }^{7}$ a preservação digital tem a ver com a capacidade social e humana em reagir de modo ágil, criativo e flexível, com soluções novas para problemas novos. Assim, preservação digital diz respeito à aplicação de estratégias capazes de viabilizar a permanência continuada de informações para uso das futuras gerações, preocupando-se com os impactos das mudanças tecnológicas. Para a International Federation of Library Associations and Institutions (IFLA) ${ }^{8}$, preservar inclui todos os aspectos gerenciais, financeiros e humanos, para prover acondicionamento e guarda adequada, além de políticas, atividades técnicas e procedimentos envolvidos na preservação, não apenas dos próprios documentos, mas também das informações contidas neles.

Sayão ${ }^{9}$ sublinha que não existe preservação digital sem a garantia de acesso contínuo ao conteúdo intelectual dos documentos, e isso depende fortemente da expectativa de vida dos sistemas de acesso. De acordo com o autor, requer-se algo além da preservação do artefato físico, ou seja, é preciso levar em conta outras dimensões do problema que dizem respeito à preservação: 
- Física das mídias e sua renovação, quando se fizer necessário;

- Lógica com foco nos formatos e dependência de hardware e software que mantenham legíveis e interpretáveis as cadeias de bits;

- Intelectual, que tem como foco o conteúdo intelectual, sua autenticidade e integridade.

Na garantia de acesso é preciso considerar, ainda, a aplicação de estratégias de preservação para documentos digitais, muito embora ainda não exista uma estratégia capaz de dar conta de toda a gama de problemas relacionados à preservação digital. Ainda assim, pode-se dizer, que, ao longo dos anos, foram analisadas e desenvolvidas técnicas e metodologias para reduzir a perda da informação e mitigar as vulnerabilidades dos sistemas e repositórios.

Algumas dessas estratégias resumidas e descritas por Sayão $0^{9}$ dizem respeito a: preservação da tecnologia, que se baseia na criação de museus tecnológicos que preservem réplicas de plataformas de hardware e software para uso no futuro; a emulação que tem como premissa preservar o objeto digital junto ao seu software original; a migração que consiste em um conjunto de atividades que copia, converte ou transfere a informação de um patamar tecnológico para outro mais atualizado e o encapsulamento, que cria estruturas físicas ou lógicas que reúnem elementos para a interpretação dos objetos digitais - do próprio objeto e dos metadados correspondentes.

No tocante à padronização dos processos, é indicado o uso de padrões que tornam esses processos mais fáceis e mais baratos. No entanto, esses padrões não foram criados, via de regra, para a preservação digital, embora funcionem na facilitação da comunicação e na ação entre os vários domínios que concorrem para essa preservação. Um exemplo são os padrões de metadados, ou metadados de preservação.

Conceituados por Sayão9 como "informações estruturadas que descrevem, explicam, localizam, ou possibilitam que um recurso informacional seja fácil de recuperar, usar ou gerenciar" (p. 5), os metadados visam padronizar os dados de busca para facilitar a interoperabilidade e acessibilidade e estão orientados para a gestão da preservação digital.

Para Márdero Arellano ${ }^{10}$, a preservação assume diferentes significados dependendo do contexto em que está sendo desenvolvida. Na Ciência da Informação ela refere-se à infraestrutura e ao comprometimento institucional necessário para proteger a informação representada digitalmente. Já para os cientistas da computação, essa seria uma maneira de atenuar a obsolescência tecnológica e aumentar a memória humana. Para arqueólogos e historiadores, a preocupação é a de que seja possível, no futuro, desenvolver e contextualizar a história da sociedade atual - quase completamente já registrada em formato digital -, através das evidências do mundo em que vivemos.

Dessa maneira, somos levados a lembrar que é a partir da marcante perecibilidade dos documentos digitais, da rápida maturação ou obsolescência dos instrumentos tecnológicos, que o desenvolvimento das estratégias precisam estar alicerçados não somente como garantia da manutenção do acesso aos recursos de informação digital, mas também como "garantia do contínuo acesso aos conteúdos e funcionalidades dos recursos eletrônicos originais" ${ }^{\prime 6}$ (p. 16).

Circunscreve-se, nessa conformidade, que as questões relacionadas à preservação digital buscam conscientizar instituições e profissionais que trabalham com a informação, independente de suporte ou formato, que há uma crise iminente no que tange à perda de informações fragilizadas por conta do ambiente em que estão armazenadas.

Não obstante, as experiências acumuladas com a gestão dessa informação têm mostrado que as medidas imediatas que são tomadas para mitigar os riscos incidentes, no ambiente digital, ainda não são suficientes. Para tanto, faz-se necessário um aprofundamento do conhecimento científico sobre as atividades de controle, que buscam identificar, analisar e avaliar esses riscos. Nesse sentido, conforme Tavares ${ }^{11}$, o risco se coloca 
como um desafio para os processos de preservação do acervo digital, e o gerenciamento das estratégias precisa ser implementado através de práticas que permitam cobrir todo o ciclo de vida do objeto digital.

\section{Redes sociais de colaboração científica}

A colaboração científica faz parte do processo de construção da ciência e já vem sendo difundida há muito tempo. Nesse novo cenário, marcado pelas TDIC, esse modo de fazer ciência intensificou-se, uma vez que essa nova organização demanda múltiplos saberes e diversas competências que estimulam o compartilhamento de conhecimentos entre os pares, seja no desenvolvimento de pesquisas, seja na escrita de um artigo científico. De acordo com Vanz e Stumpf ${ }^{12}$ : "A colaboração científica tem sido definida como dois ou mais cientistas trabalhando juntos em um projeto de pesquisa, compartilhando recursos intelectuais, econômicos e/ou físicos" (p. 44).

Na comunicação científica, essa colaboração potencializou a formação de redes sociais que buscam compartilhar conhecimento por meio da interação e troca de informação com seus semelhantes. De acordo com Morigi e $\mathrm{Krebs}^{13}$, a rede social produz um sistema de compartilhamento de esquemas explicativos, crenças e valores que traz um conhecimento em comum que transfiguram as culturas. Para Pisciotta ${ }^{14}$, nossa sociedade funciona em rede composta por sub-redes que se ligam por uma infinita articulação entre pares. Essa autora elenca duas grandes categorias de redes sociais: as formalmente organizadas e as informalmente organizadas. E também cita duas sub-redes: as redes sociais pessoais e as redes sociotécnicas. Pode-se dizer que as redes sociais pessoais podem representar as redes informalmente organizadas, pois estas não estão preocupadas em se organizar para que haja fluidez da informação de modo que a rede funcione, no entanto, elas se dedicam para que as relações fluam, acontecendo a comunicação.

Por sua vez, a comunicação científica está inserida nas redes sociotécnicas, que são as formalmente organizadas e têm a preocupação que informações especializadas circulem entre os membros da comunidade. Vale ressaltar que a comunicação científica pode acontecer por meio de canais formais e informais e está inserida em um contexto de uma rede maior, instituída por uma intenção explícita e consciente de fazer com que as pessoas e/ou entidades se interliguem em redes, ou seja, a comunicação científica interliga tanto pontos de redes formais quanto de redes informais. Segundo Castells ${ }^{15}$, rede social é "um conjunto de nós interconectados" (p. 498), essa rede pode expandir de forma ilimitada, integrando novos nós desde que consigam comunicar-se dentro da rede, ou seja, desde que compartilhem os mesmos códigos de comunicação.

Marteleto ${ }^{16}$ diz que redes sociais são o "conjunto de participantes autônomos" (p. 72) que unem ideias e recursos, objetivando valores e interesses comuns. Recuero ${ }^{17}$ especifica que essa rede é a composição de dois elementos: os atores e suas conexões. Os atores são as pessoas, instituições ou grupos, assim como os nós da rede. Já as conexões são as interações ou laços sociais.

O conhecimento dessas redes é baseado na observação dos dados, na descoberta das relações existentes entre os atores e em como pode-se inferir informações úteis dessas relações. Castells ${ }^{15}$ coloca que as redes são sistemas organizacionais capazes de reunir indivíduos e instituições, de forma voluntária e democrática, em torno de objetivos e/ou temáticas comuns, e são estabelecidas por relações horizontais que supõem o trabalho colaborativo e participativo. É nesse contexto que nascem as redes de colaboração em preservação digital, como uma resposta aos problemas oriundos do contexto digital que trouxeram incertezas sobre a fragilidade e vulnerabilidade dos acervos, mas também iluminam a importância da garantia do acesso e da preservação, fazendo com que instituições e pesquisadores colaborem para o desenvolvimento de bases teóricas e práticas para enfrentamento dos problemas.

Gouveia Junior ${ }^{18}$ afirma que essas redes são capazes de enxertar capital social em um nível institucional e, assim, conceder benefícios à sociedade, bem como potencializar a aprendizagem, a mobilidade social e 
o desenvolvimento econômico. Nesse entendimento, o capital social é a interação que une indivíduos em torno de objetivos comuns e evidencia relações de colaboração, reciprocidade e confiança mútua, tornando os indivíduos mais fortes, e deixando evidente a estrutura de redes por traz desse conceito.

As redes de colaboração, a partir de uma perspectiva de rede social, estão cada vez mais presente nas organizações, onde o trabalho em equipe tem se tornado uma estratégia de negócio e um instrumento para se vencer os desafios do novo mundo globalizado. A complexidade crescente desses desafios requer habilidades multidisciplinares. Dessa forma, a imagem popular do 'gênio solitário' vai aos poucos sendo substituída pela crença de que 'duas cabeças pensam melhor do que uma'. Nessa perspectiva, a colaboração também é vista como parte fundamental do desenvolvimento das infraestruturas organizacionais, que sustentam os repositórios institucionais e as redes de preservação digital de forma mais geral, como sintetiza Galindo ${ }^{19}$.

\section{OS CAMINHOS DA PESQUISA}

Trata-se de estudo exploratório e descritivo, com abordagem quali-quantitativa, da produção científica e das redes sociais colaborativas de pesquisadores que abordam a temática da preservação digital, no campo da Ciência da Informação, no Brasil. Para tanto, toma-se como referência a abordagem de Ginzburg ${ }^{20}$, que propõe o método indiciário para as Ciências Humanas e Sociais, possibilitando a investigação por meio de sinais/indícios fundamentados na experiência e observação do cientista 'caçador', para alcançar e desenvolver novos conhecimentos. A ideia subjacente a esse método é a de que, embora a realidade seja opaca, existem zonas privilegiadas - sinais, indícios, pistas - que permitem decifrá-la. E esse é o caminho de nossa pesquisa.

Por sua vez, em seu estudo sobre sistemas de recuperação da informação, Araújo apud Freire ${ }^{21}$ (p. 7), descreve seu processo de busca de indícios, ao qual denomina brauseio (browsing), o qual se aplicaria "às ações de andar a esmo, ou deambular”, tal como o 'zapear' a informação em uma base de dados, selecionando uma amostra válida para uma pesquisa. Para essa autora, "o brauseio é essencialmente visual e tem um forte componente de 'acesso direto'”21.

Nesta pesquisa, o brauseio resume-se à busca de indícios sobre a produção científica em preservação digital, no território dos periódicos científicos brasileiros indexados na Base de Dados em Ciência da Informação (BRAPCI), publicada pela Universidade Federal do Paraná. Esta é uma base de dados reconhecida na área de Ciência da Informação, que indexa referências e resumos de 57 periódicos nacionais impressos e eletrônicos da área, desde 1972, sendo que destes periódicos, 40 estão em atividade e 17 estão descontinuados ${ }^{22}$.

Para a realização da busca, nesse território, utilizaram-se as 'artimanhas de caçador' para filtrar os resultados na base de dados, com termos delimitadores, no caso, a palavra-chave 'preservação digital', entre aspas duplas, evitando assim a recuperação dos termos separados, sendo o campo de pesquisa delimitado ao título, para evitar artigos que fugissem da temática. O período de publicação foi delimitado de 2000 a 2019, considerando que as publicações sobre essa temática tiveram início na década de 1990, mas somente foram disseminadas a partir do ano 2000, conforme indica a literatura da área, embora essas primeiras publicações possam não estar contempladas nos periódicos científicos eletrônicos.

$\mathrm{Na}$ análise de coautoria foi realizado um recorte, por se tratar de um exercício para a análise final da pesquisa, que ainda se encontra em andamento, e por considerarmos os resultados dessa análise uma amostra significativa das autorias e coautorias realizadas no contexto da pesquisa, e além disso, de pesquisas mais recentes que configuram o contexto atual das pesquisas sobre preservação digital no Brasil. Dessa forma, foram considerados os autores que publicaram entre 2016 e 2019 para formulação da rede de autores e coautores da rede. 
Para identificar os atores e as relações que compõem as redes de colaboração em preservação digital, assim como a densidade e centralidade dessa rede, foi utilizada a metodologia de Análise de Redes Sociais (ARS), que de acordo com Marteleto ${ }^{16}$ é: “[...] o meio para realizar uma análise estrutural cujo objetivo é mostrar em que a forma da rede é explicativa dos fenômenos analisados" (p. 72).

O uso dessa metodologia em estudos da área da Ciência da Informação, de acordo com a autora, pode, por exemplo, ajudar a compreender os fenômenos dos fluxos de informação, a partir das redes sociais. A análise de redes é abordada como uma forma de compreender a dinâmica de relações, identificar fluxos de informação, mecanismos e agentes de poder e analisar ambientes complexos de interações. Para melhor exploração e visualização dos dados foram utilizados os softwares Microsoft Excel, Ucinet 6.0 e NetDraw 2.10. O grafo de visualização foi disposto no NetDraw.

\section{PRESERVAÇÃO DIGITAL NO BRASIL 2000-2019}

A seguir, apresentam-se os dados e comentários sobre os resultados da pesquisa na BRAPCI sobre a literatura que aborda a temática da preservação digital, seguindo-se os resultados da análise das redes sociais estabelecidas entre os pesquisadores/autores e as categorias temáticas de interesse estudadas nas publicações.

\section{Literatura disponível na BRAPCI}

O levantamento na BRAPCI, considerando o período de 2000 a 2019, recuperou um conjunto de publicações totalizando 80 artigos publicados nos periódicos brasileiros sobre a temática em questão. Desse conjunto foram selecionados 61 artigos para análise, pois os outros não correspondiam às variáveis nomeadas na busca, por exemplo: não se tratavam de artigos científicos (editorial, dossiê, slides), ou foram publicados em Anais de eventos, que não eram foco da pesquisa, ou ainda estavam duplicados na base. Os primeiros resultados do levantamento estão apresentados no Quadro 1, conforme segue:

Quadro 1 - Periódicos científicos: instituição, ano de publicação, quantidade de artigos

(continua)

\begin{tabular}{|l|l|l|l|}
\hline \multicolumn{1}{|c|}{ Periódicos } & \multicolumn{1}{|c|}{$\begin{array}{c}\text { Instituição } \\
\text { responsável pelo } \\
\text { periódico }\end{array}$} & $\begin{array}{c}\text { Ano de } \\
\text { Publicação }\end{array}$ & $\begin{array}{c}\text { Qtde. de } \\
\text { artigos } \\
\text { publicados }\end{array}$ \\
\hline Acervo & Arquivo Nacional & 2016 & 1 \\
\hline AtoZ: Novas Práticas em Informação e Conhecimento & UFPR & 2012 & 1 \\
\hline Biblionline & UFPB & 2015 & 1 \\
\hline $\begin{array}{l}\text { BIBLOS - Revista do Instituto de Ciências Humanas e da } \\
\text { Informação }\end{array}$ & FURG & 2010 & 1 \\
\hline Brazilian Journal of Information Science & Unesp Marília & 2017 & 1 \\
\hline Ciência da Informação & IBICT & 2012 & 10 \\
\hline Ciência da Informação em Revista & UFAL & 2018 & 1 \\
\hline DataGramaZero & Inativa & $2004 ; 2006$ & 2 \\
\hline Em Questão & UFRGS & 2019 & 1 \\
\hline $\begin{array}{l}\text { Encontros Bibli: Revista Eletrônica de Biblioteconomia e } \\
\text { Ciência da Informação }\end{array}$ & UFSC & $2010 ; 2011 ;$ & 3 \\
\hline
\end{tabular}


(conclusão)

\begin{tabular}{|c|c|c|c|}
\hline Periódicos & $\begin{array}{l}\text { Instituição } \\
\text { responsável pelo } \\
\text { periódico }\end{array}$ & $\begin{array}{c}\text { Ano de } \\
\text { Publicação }\end{array}$ & $\begin{array}{l}\text { Qtde. de } \\
\text { artigos } \\
\text { publicados }\end{array}$ \\
\hline $\begin{array}{l}\text { InCID: Revista de Ciência da Informação e } \\
\text { Documentação }\end{array}$ & Usp & 2012 & 1 \\
\hline Informação@Profissões & UEL & $2013 ; 2015$ & 2 \\
\hline Informação \& Sociedade: Estudos & UFPB & $2014 ; 2016$ & 2 \\
\hline Informação \& Informação & UEL & 2018 & 1 \\
\hline Informação em Pauta & UFC & 2019 & 1 \\
\hline Informação \& Tecnologia & GT8 Enancib & $\begin{array}{l}2015 ; 2017 ; \\
2018(2)\end{array}$ & 4 \\
\hline Liinc em Revista & IBICT & 2015 & 1 \\
\hline Perspectivas em Ciência da Informação & UFMG & $\begin{array}{l}2013 ; 2015 ; \\
2018(2)\end{array}$ & 4 \\
\hline $\begin{array}{l}\text { Pesquisa Brasileira em Ciência da Informação e } \\
\text { Biblioteconomia }\end{array}$ & UFPB & $2017 ; 2019$ & 2 \\
\hline Ponto de Acesso & Ufba & 2017 & 1 \\
\hline Revista Ágora & UFSC & 2014 & 1 \\
\hline Revista Brasileira de Biblioteconomia e Documentação & UEL & $2017(2)$ & 2 \\
\hline $\begin{array}{l}\text { Revista Digital de Biblioteconomia e Ciência da } \\
\text { Informação }\end{array}$ & Unicamp & $\begin{array}{l}2011 ; 2015 ; \\
2016(7) ; \\
2017\end{array}$ & 10 \\
\hline Revista Ibero-Americana de Ciência da Informação & UnB & $\begin{array}{l}2015 ; 2016 \\
(2) ; 2018(4)\end{array}$ & 7 \\
\hline
\end{tabular}

Fonte: Dados da pesquisa (2020).

Como destacado na revisão teórica, a temática de preservação digital começou a ser abordada no Brasil na década de 1990, mas só a partir do ano 2000 foram identificadas publicações científicas sobre o tema ${ }^{1}$. Conforme nos mostram os resultados apresentados no Quadro 1, as publicações indexadas na BRAPCI iniciam-se em 2004 e mesmo descontinuadas seguem sendo registradas até o momento atual. É oportuno pontuar que a preservação digital, enquanto tema de interesse, por englobar problemas técnicos, tecnológicos, interdisciplinares e sociais, deve estar sempre na agenda da Ciência da Informação, pois demanda conhecimentos novos a todo tempo, buscando superar as adversidades do contexto complexo e vulnerável em que a informação é registrada.

Os periódicos científicos, parte importante no processo de comunicação científica, divulgaram as pesquisas aqui analisadas através de 24 publicações. Destacam-se, nesse contexto, dois periódicos: a revista Ciência da Informação, publicada pelo Instituto Brasileiro de Informação em Ciência e Tecnologia (IBICT), e a Revista Digital de Biblioteconomia e Ciência da Informação, vinculada ao Sistema de Bibliotecas da Universidade Estadual de Campinas (Unicamp). O primeiro periódico publicou, em 2012, um número especial com dez artigos, buscando trazer reflexões e estabelecer a importância da discussão sobre preservação digital na área da Ciência da Informação. O segundo periódico publicou também dez artigos ao longo de quatro anos, sendo que sete desses compunham um número especial publicado em 2016 com o tema 'Preservação digital e sua prática nos diversos campos dos saberes', como forma de divulgar e enriquecer as iniciativas e práticas de preservação digital no Brasil. No corpus da pesquisa, esses números 
especiais foram responsáveis por um terço das publicações sobre o tema em relação aos demais periódicos, no período pesquisado.

Observa-se ainda, no Quadro 1, que os anos com maior número de publicações foram 2012 (13 artigos), 2016 (11 artigos), 2018 (10 artigos), 2015 e 2017 com sete artigos cada, demostrando assim que existe um interesse pelo tema na Ciência da Informação, fomentado principalmente pelos números especiais propostos por periódicos, conforme acima citado. Esse interesse vem aumentando gradativamente, visto que os artigos publicados em 2018 foram divulgados em cinco periódicos diferentes da área, sendo a temática distribuída em várias regiões do país. Os números especiais são importantes, pois impulsionam a produção sobre o tema, mas a divulgação em periódicos diferentes, em diferentes regiões, também se faz necessária para que um maior número de usuários possam ter acesso ao material divulgado.

No Quadro 2, podemos confirmar o número de instituições brasileiras as quais os autores estão filiados e onde desenvolvem suas pesquisas sobre preservação digital, disseminando o resultado dessas pesquisas em periódicos brasileiros.

Quadro 2 - Quantidade de publicações por instituição

\begin{tabular}{|l|l|l|}
\hline Instituição & $\begin{array}{c}\text { Qtde. de } \\
\text { autores }\end{array}$ & $\begin{array}{c}\text { Qtde. de } \\
\text { Publicações }\end{array}$ \\
\hline IBICT & 12 & 9 \\
\hline UFSM & 12 & 8 \\
\hline Unesp & 8 & 3 \\
\hline UFSC & 8 & 4 \\
\hline UFRGS & 7 & 3 \\
\hline UnB & 7 & 6 \\
\hline UFPE & 7 & 3 \\
\hline UFSCar & 6 & 4 \\
\hline UFPB & 6 & 3 \\
\hline Ufba & 5 & 2 \\
\hline UniRio & 4 & 2 \\
\hline UFPA & 4 & 3 \\
\hline Unicamp & 4 & 3 \\
\hline UFG & 3 & 1 \\
\hline Usp & 3 & 3 \\
\hline FURG & 2 & 1 \\
\hline FESP & 2 & 1 \\
\hline UFC & 2 & 2 \\
\hline UFMG & 2 & 1 \\
\hline UFJF & 1 & 1 \\
\hline UFF & 1 & 1 \\
\hline UFPR & 1 & 1 \\
\hline UFES & 1 & 1 \\
\hline CNEN & 1 & 1 \\
\hline Câmara dos & 1 & 1 \\
\hline Deputados & & \\
\hline & & \\
\hline
\end{tabular}

Fonte: Dados da pesquisa (2020).

No total, identificamos 25 instituições e destas apenas uma é instituição privada e outra não é instituição de ensino superior, o que demonstra que essas pesquisas têm sido desenvolvidas no núcleo de instituições 
públicas e, principalmente, nas universidades federais. No Quadro 2, podemos observar que a distribuição espacial dessas instituições está concentrada na região Sudeste, com dez instituições; Sul e Centro-Oeste, com cinco instituições cada; o Nordeste com quatro instituições; e o Norte com apenas uma instituição.

O IBICT e a Universidade Federal de Santa Maria (UFSM) destacaram-se, nesse contexto, tanto em número de filiação de autores, 12 cada, quanto em número de publicações, nove e oito, respectivamente. No contexto do IBICT, infere-se que essas publicações são fruto de pesquisas desenvolvidas no âmbito da Rede Cariniana, que se configura como uma rede de serviços de preservação digital de documentos eletrônicos brasileiros, com o objetivo de garantir seu acesso contínuo a longo prazo. Além disso, desde 2002, o IBICT vem destacando a preservação digital como um dos temas mais importantes da sua missão. Na UFSM, depreende-se que a criação dos cursos de Arquivologia e do Programa de Pós-Graduação em Patrimônio Cultural impulsionou essas publicações, destacando-se o professor Daniel Flores, que participa como coautor em sete publicações. O professor é vinculado à Linha de Pesquisa Patrimônio Documental Arquivístico e desenvolve projetos e pesquisas na área de Gestão Eletrônica de Documentos Arquivísticos. Desataca-se, ainda nesse contexto, que foi considerada a afiliação dos autores no período das publicações e nas informações contidas nas publicações ou nos metadados da BRAPCI.

\section{Redes sociais de colaboração em preservação digital}

$\mathrm{Na}$ análise bibliométrica, foram identificados 133 autores que publicaram dentro do conjunto de publicações analisadas. Para a análise, os autores que publicaram mais de um artigo, foram considerados na soma final apenas uma vez, sendo o número final de 110 autores, entre autoria individual e coautoria.

$\mathrm{Na}$ análise sobre autorias, foi possível observar que dos 61 artigos analisados dez foram escritos por autoria individual. Desses apenas um autor publicou dois artigos, (Innarelli, em 2011 e 2012), os outros oito artigos de autoria individual foram escritos por autores diferentes. É possível ressaltar que dois autores que se destacaram nas coautorias, a saber: Flores (com seis artigos publicados em 2014, 2015, 2016, 2017, 2018 e 2019) e Márdero Arellano (com quatro artigos, em 2006, 2012, 2016 e 2018), o último também teve uma publicação individual em 2012. Evidencia-se, ainda, quatro duplas de coautores que publicaram juntos dois dos artigos sobre a temática, demonstrando uma parceria consolidada nesses grupos.

$\mathrm{Na}$ análise de redes sociais, foram selecionados 66 autores que publicaram dentro do escopo da pesquisa, sendo que apenas três destes publicaram artigos de forma individual (Bodê, em 2015; Boeres, em 2012; Santos, em 2016), e os outros publicaram de forma colaborativa, formando assim as coautorias que aqui serão analisadas. Nesse contexto, observou-se a colaboração de uma dupla de autores que publicaram dois artigos sobre o tema: Manfré e Sousa, ambos em 2017.

Como destacam Leta e Canchumani ${ }^{3}$, a base para análise de redes colaborativas na ciência encontra-se nas autorias, e essas análises partem das informações sobre as relações existentes entre pares e autores. Considerando as coautorias nas produções científicas sobre preservação digital, destacam-se as publicações de Flores, Márdero Arellano, Pinto e Pavão, que foram os atores da rede que mais se destacaram nesse quesito. Conforme Figura 1, Flores publicou quatro artigos em colaboração, sendo o ator da rede que possui mais ligações, seis ao todo. Os outros que se destacaram publicaram dois artigos cada, sendo que Pinto possui um maior número de ligações, quatro; enquanto Márdero Arellano e Pavão possuem três ligações cada. Destaca-se, ainda, que apesar de possuir quatro ligações, Santos não foi apontada nesse contexto por se tratar da publicação de um único artigo em coautoria. 


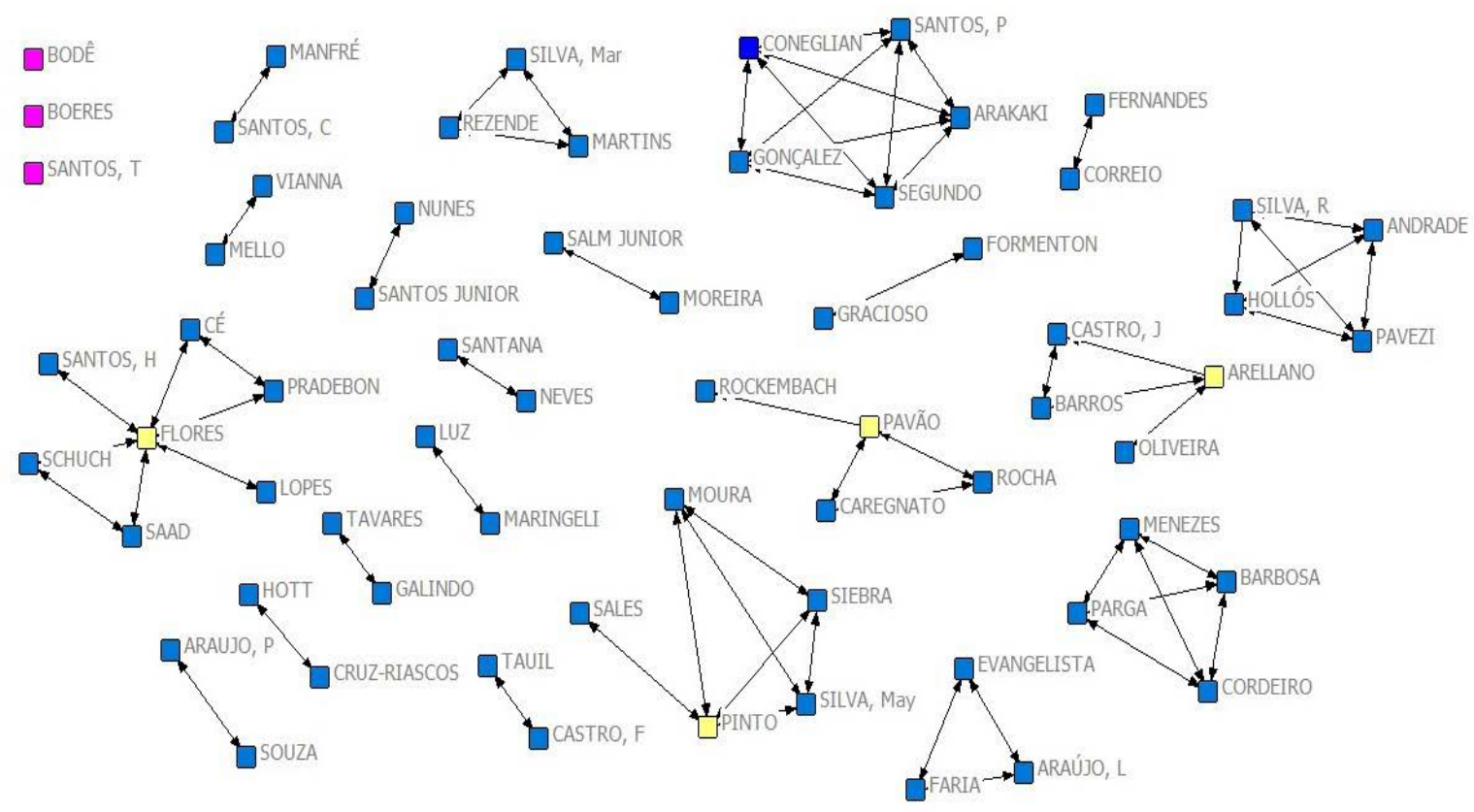

Figura 1 - Rede colaborativa sobre preservação digital no Brasil (2016-2019) Fonte: Dados da pesquisa (2020).

Vale ressaltar que se trata de uma rede fragmentada, pois não há uma centralidade, ou seja, não existe um ator central que lidere as ações dos outros grupos. O que se percebe é a formação de sub-redes, e nelas é possível perceber a colaboração e centralidade de um ator. Dessa forma, a análise dessa rede indicou uma densidade de apenas o,123, sendo considerada fraca ou de baixa conectividade. Essa densidade é calculada pelas relações existentes na rede, as relações possíveis e os nós (atores).

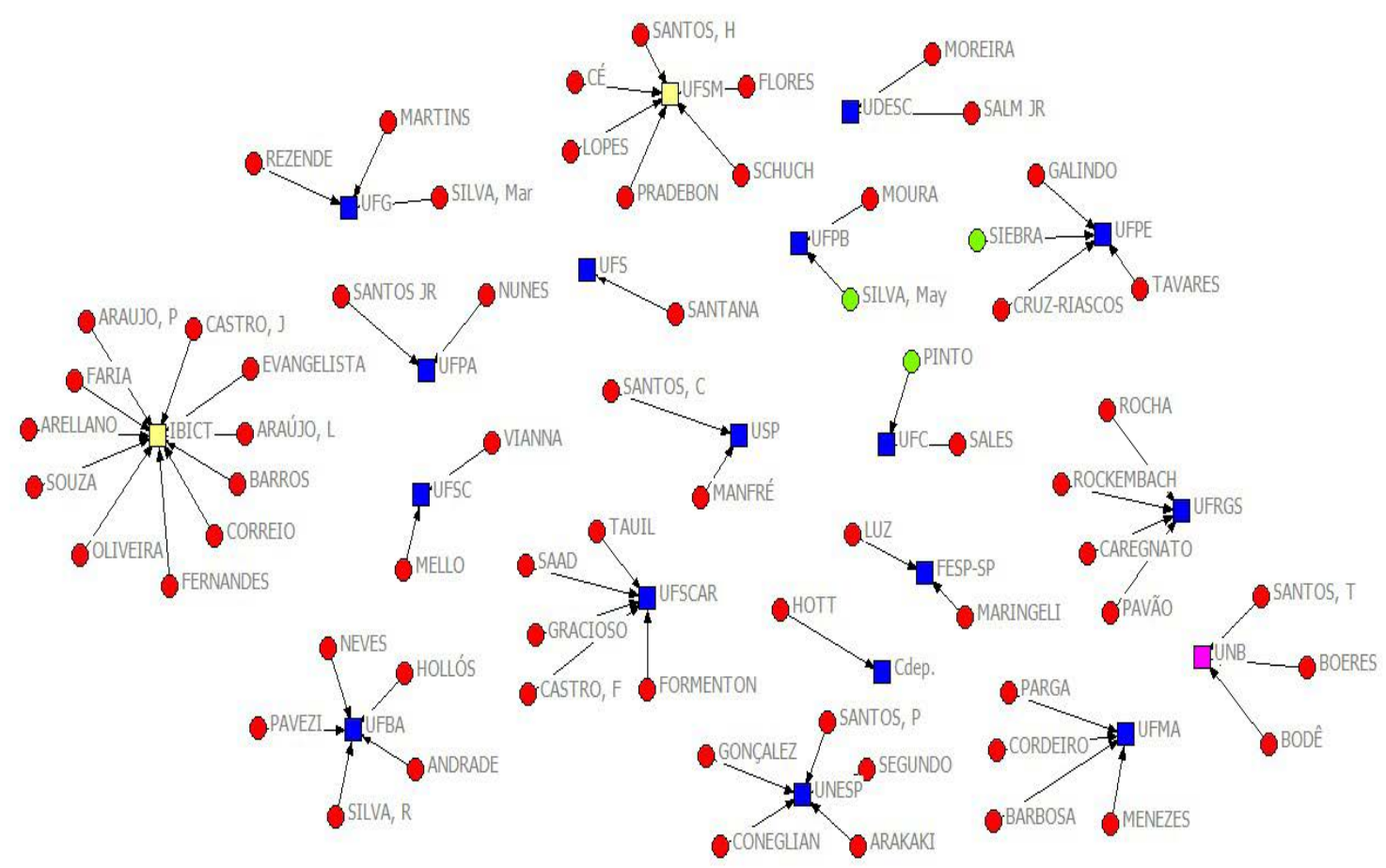

Figura 2 - Rede de vínculo institucional dos atores da rede Fonte: Dados da pesquisa (2020). 
A Figura 3 confirma as instituições as quais esses autores estão filiados e demonstra ainda que as relações entre os autores estão ou são fortalecidas por esse laço institucional. Nota-se também a existência de vínculos interinstitucional, ainda que essa identificação não seja foco desta pesquisa. Assim, descreve-se que foram identificadas dezenove instituições concentradas nas regiões Nordeste, com seis instituições; Sudeste, com cinco; e Sul, com quatro. Norte e Centro-Oeste apresentam apenas uma instituição cada, e duas ficam no Distrito Federal, alcançando assim todas as regiões do Brasil. Muito embora, no tocante à filiação autor-instituição, as regiões Sudeste e Sul são as que mais se destacaram, conforme análise anterior. Evidencia-se, ainda, nessa figura a instituição UnB, que possui três afiliações e esses autores foram os que publicaram de forma individual.

\section{Categorias temáticas de interesse nos artigos}

A partir de informações retiradas dos títulos dos artigos analisados, formularam-se categorias temáticas que representam a abordagem dada pelos autores nas aproximações com a preservação digital. Destacamse, nessa perspectiva, categorias como: Documentos; Políticas; Produção Científica; Competências; Repositórios; Instituição; Padrões e Normas; Periódicos; Gestão; Ontologia; Rede Cariniana; Obsolescência; Recuperação da Informação; Memória; Ciência da Informação; Curadoria Digital; Direito Autoral; Importância e Mídias Sociais. Com isso foi possível criar uma nuvem de palavras com as temáticas mais abordadas nos artigos analisados.

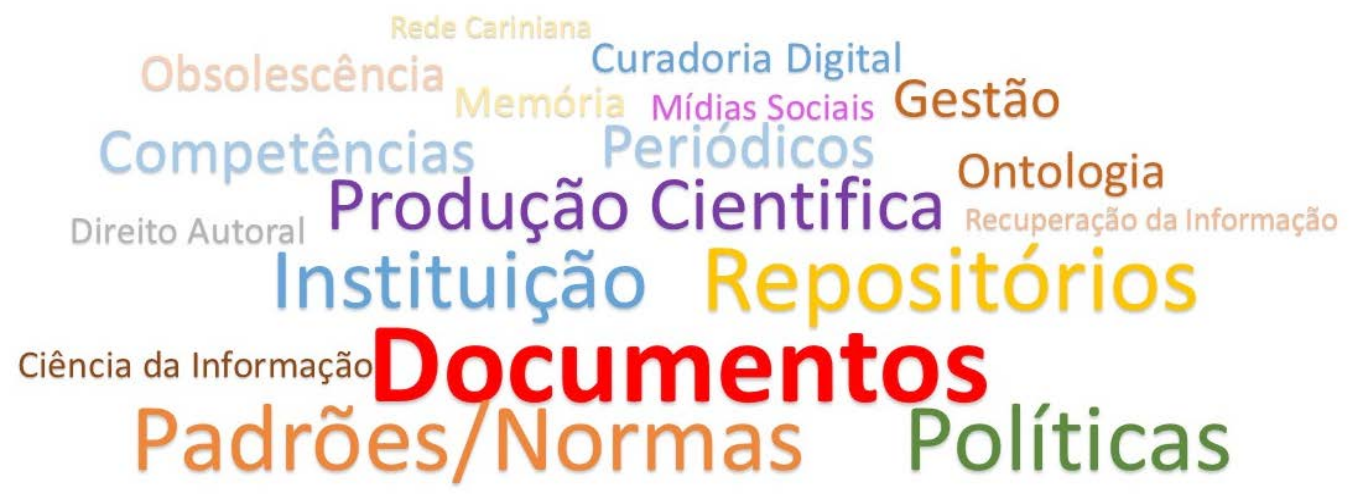

Figura 3 - Nuvem de palavras dos temas relacionados aos títulos dos artigos Fonte: Dados da pesquisa (2020).

Diante do exposto na Figura 3, é possível observar que a categoria de 'Preservação de documentos digitais' é uma das mais destacadas: nove artigos trataram dessa temática, e as abordagens vão de documentos de arquivos, fotografias, videogames a e-books. A preocupação com a fragilidade e vulnerabilidades dos documentos digitais foram o impulso inicial para as pesquisas em preservação digital, principalmente no que tange aos documentos de arquivo, visto que foi na arquivística que surgiram os primeiros estudos sobre o tema.

'Repositórios' e 'Padrões e Normas' são categorias que também foram bem exploradas nos artigos, com sete publicações cada. Essas temáticas sempre estão em alta, quando se trata de preservação digital, pois os repositórios (digital, institucional, de dados ou temáticos) foram criados, via de regra, para viabilizar o acesso a longo prazo aos documentos digitais, que trazem consigo questões relacionadas à autenticidade, integridade e longevidade desses documentos. Para tanto, é necessário que os repositórios adotem 'Padrões e Normas' que irão reduzir a grande variedade de processos de preservação customizados. Importante 
destacar que entre os 'Padrões e Normas' abordados nos artigos estão os padrões de metadados, o modelo de referência OAIS (Open Archival Information System), a ISO 14721 e a NBR 15472.

Outra categoria que se destaca é a de 'Políticas', com sete artigos que trataram dessa temática. A política de preservação digital é vista como uma das atividades mais importantes na consolidação de um acervo digital. Nesta política é preciso levar em consideração aspectos organizacionais, legais e técnicos, que devem contemplar desde a seleção dos objetos ou documentos digitais até o planejamento contra desastres, além do gerenciamento dos recursos digitais, a fim de mantê-los estáveis e confiáveis. Os artigos que tratam dessa temática apresentam modelos de políticas e destacam a importância delas para as instituições.

No tocante à categoria 'Instituição', foram seis os artigos que discutiram a questão da preservação digital em bibliotecas, museus, arquivos e universidades, com a temática envolvendo desde questões técnicas e organizacionais até problemas relacionados à gestão de processos administrativos e, ainda, a implantação de ações de salvaguarda de coleções digitais.

Outra categoria temática observada foi a de 'Produção Científica', com quatro artigos descrevendo pesquisas que tiveram como foco a produção científica sobre preservação digital, mostrando a relevância de se aplicarem técnicas bibliométricas para analisar a evolução de uma temática dentro de um campo de pesquisa. Nesse mesmo passo, uma categoria que se aproxima dessa discussão é a dos 'Periódicos' científicos eletrônicos, por se tratar de meios de comunicação científica, onde se publicam e disseminam os resultados de pesquisas. Foram três artigos que abordaram essa temática e trataram de aspectos técnicos demandados pela preservação digital, assim como de políticas para periódicos e relatos de experiência.

As 'Competências' dos profissionais envolvidos nesse contexto também foi uma questão explorada em três dos artigos recuperados na pesquisa, e esta foi e ainda é uma questão debatida entre pesquisadores do tema, pois as iniciativas de preservação digital demandam recursos humanos com determinados conhecimentos e competências, uma vez que a falta de preparação de profissionais habilitados para gerir acervos digitais ainda é um obstáculo a ser vencido. Tais questões são consideradas ameaça para a perda de informações cruciais.

\section{CONSIDERAÇÕES FINAIS}

No presente estudo foi possível identificar, na literatura analisada, que a produção científica sobre preservação digital, no contexto da Ciência da Informação, teve um crescimento no período analisado (2000 a 2019). Os anos de 2012 e 2016 concentraram o maior número das publicações indexadas na BRAPCI. Destaca-se que essas publicações foram impulsionadas por duas edições especiais nos seguinte periódicos: na Ciência da Informação, do IBICT, em 2012; e na Revista Digital de Biblioteconomia e Ciência da Informação, da Unicamp, em 2016.

Observou-se a presença de 110 autores que publicaram sobre a temática no período analisado, com um total de 61 artigos identificados no contexto da pesquisa. Sobressai, desses números, que apenas dez desses artigos foram publicados por autor individual, o que evidencia a atividade de colaboração científica, comum no contexto de desenvolvimento e consolidação de temas novos e complexos, como é o caso da preservação digital. No momento da publicação, os autores estavam filiados a 25 instituições; sendo apenas uma delas da iniciativa privada, e outra não sendo instituição de ensino superior. Destacam-se, nesse contexto, o IBICT e a UFSM, tanto em número de filiação de autores doze cada, quanto em número de publicações, nove e oito, respectivamente.

Dos títulos dos artigos analisados foram formuladas categorias conceituais, através da abordagem dada pelos autores nas aproximações com a preservação digital. Nessa perspectiva, os conceitos que mais se destacaram foram: 'Preservação de documentos digitais' que contou com nove artigos com abordagens que foram desde documentos de arquivos, fotografias, videogames a e-books; e as categorias 'Repositórios' e 
'Padrões e Normas', com sete publicações cada uma, trataram de instrumentos e ferramentas que buscam facilitar o acesso aos documentos digitais, garantindo assim, autenticidade, integridade e longevidade a esses documentos.

Ao analisar a rede de colaboração científica sobre preservação digital, na literatura indexada na BRAPCI, verificou-se que se trata de uma rede fragmentada, pois a colaboração acontece apenas por meio de subredes, com atores que colaboram dentro de um contexto específico, com membros vinculados à mesma instituição. Esse cenário, no entanto, não descaracteriza a rede colaborativa, uma vez que essa colaboração é fortalecida pela produção científica disseminada nos periódicos brasileiros, no período de 2016 a 2019.

Para análise dessa rede de colaboração, o indicador utilizado foi o de coautoria dos artigos levantados na busca, pois é o indicador mais utilizado para este fim. Assim, obteve-se uma rede de coautoria com 66 nós (autores) e 429 relações possíveis. Quatro atores da rede se destacaram em número de ligações: Flores (6), Pinto (4), Márdero Arellano e Pavão (3) - esses atores também foram os que mais colaboraram nos artigos analisados.

Em suma, percebe-se a incursão e crescimento da temática preservação digital no contexto das publicações científicas nos periódicos da Ciência da Informação no Brasil, sendo que estas ainda são consideradas incipientes, principalmente quando se pensa no período de 20 anos de pesquisas e publicações que vem sendo desenvolvidas.

O cenário científico nacional necessita ainda de engajamento de pesquisadores que se envolvam nessa rede de colaboração sobre a temática. Assim, tornam-se necessárias outras pesquisas e publicações que apoiem a disseminação do tema na comunidade científica e na sociedade como um todo. A expansão dessa busca em anais de eventos, em repositórios digitais abrangendo as teses e dissertações podem trazer novos indícios para futuras pesquisas e práticas favoráveis a preservação de acervos digitais. A natureza das relações entre autores também é uma variável a ser observada no futuro, para que seja possível analisar as configurações dessas redes no decorrer dos 20 anos de produção científica sobre o tema.

\section{REFERÊNCIAS}

1. Thomaz KP. A preservação de documentos eletrônicos de caráter arquivístico: novos desafios, velhos problemas [tese]. Belo Horizonte: Universidade Federal de Minas Gerais; 2004.

2. Silva AKA. Redes de coautoria em Ciência da Informação no Brasil: dinâmica na produção científica dos atores mediada pela ANCIB [Tese]. Belo Horizonte: Universidade Federal de Minas Gerais; 2012.

3. Leta J, Canchumani RML. Redes colaborativas na ciência: estudos de coautoria e cocitação. In: Tomaél MI, Marteleto RM., organizadores. Informação e redes sociais: interfaces de teorias, métodos e objetos. Londrina: Eduel; 2015. p. 109-135.

4. Saracevic T. Ciência da Informação: origem, evolução e relações. Perspect Ciênc Inf [Internet]. 1996 jan./jun. [citado em 2020 jan. 12];1(1):41-62. Disponível em: http://portaldeperiodicos.eci.ufmg.br/ index.php/pci/article/view/235/22.

5. Barreto AM. Memória e sociedade contemporânea: apontando tendências. Rev. ACB [Internet]. 2007 jul./dez. [citado em 2020 jan. 22];12(2):161-76. Disponível em: https://revista.acbsc.org.br/racb/article/ download/506/651.

6. Innarelli HC. Preservação digital: a influência da gestão dos documentos digitais na preservação da informação e da cultura. Rev Dig Bibliotecon Ci Inf [Internet]. 2011 [citado em 2019 nov. 24];9(1):7287. doi: https://doi.org/10.20396/rdbci.v8i2.1934.

7. Borba VR. Modelo orientador para construção de estratégias de preservação digital: estudo de caso do Banco de Teses e Dissertações da UFPE [dissertação]. João Pessoa: Universidade Federal da Paraíba; 2009.

8. Adcock EP, editor. Varlamoff M-T, Kremp $\mathrm{V}$, assistence. Principles for the care and handling of library material. Paris: IFLA PAC; 1998 [cited 2019 Mar 19]. (International Preservation Issues, nº 01). Available from: https://www.ifla.org/files/assets/pac/ipi/ipi1-en.pdf. 
9. Sayão LF. Uma outra face dos metadados: informações para a gestão da preservação digital. Enc. Bibli: R. Eletr. Bibliotecon. Ci. Inf. [Internet]. 2010 [citado em 2020 mar 21];15(30):1-31. Disponível em: https://periodicos.ufsc.br/index.php/eb/article/view/1518-2924.2010v15n30p1/19527.

10. Márdero Arellano MA. Critérios para a preservação digital da informação científica [tese]. Brasília: Universidade de Brasília; 2008 [citado em 2019 jun. 18]. Disponível em: https://repositorio.unb.br/ bitstream/10482/1518/1/2008 MiguelAngelMarderoArellano.pdf.

11. Tavares ALL. Análise de risco e preservação digital: uma abordagem sistêmica na Rede Memorial Pernambuco [dissertação]. Recife: Universidade Federal de Pernambuco; 2014.

12. Vanz SAS, Stumpf IR. Colaboração científica: revisão teórico conceitual. Perspect Ciênc Inf [Internet]. 2010 mai./ago. [citado em 2020 mar. 11];15(2):42-55. Disponível em: http://portaldeperiodicos.eci. ufmg.br/index.php/pci/article/view/1105/731.

13. Morigi VJ, Krebs LM. Redes de mobilização social: as práticas informacionais do Greenpeace. Inf Soc [Internet]. 2012 set./dez. [acesso em 2020 mar. 11];22(3):133-42. Disponível em: https://periodicos. ufpb.br/index.php/ies/article/view/14386/9176.

14. Pisciotta K. Redes sociais: articulação com os pares e com a sociedade. In: Población DA, Witter GP, Silva JFM, organizadores. Comunicação e produção científica: contexto, indicadores e avaliação. São Paulo: Angellara; 2006. p. 115-135.

15. Castells M. A sociedade em rede. São Paulo: Paz e Terra; 2002.

16. Marteleto RM. Análise de redes sociais: aplicação nos estudos de transferência da informação. Ci Inf [Internet]. 2001 jan./abr. [acesso em 2020 mar. 13];30(1):71-81. Disponível em: http://revista.ibict.br/ ciinf/article/view/940/977.

17. Recuero RC. Redes sociais na Internet [Internet]. Porto Alegre: Sulina; 2009 [acesso em 2020 mar. 13]. Disponível em: https://bit.ly/34TAx40.

18. Gouveia Junior M. A economia da memória: um estudo do sistema pernambucano [dissertação]. Recife: Universidade Federal de Pernambuco; 2012.

19. Galindo M. A redescoberta do trabalho coletivo. In: Azevedo Netto CX. Informação, patrimônio e memória: diálogos interdisciplinares. João Pessoa: UFPB; 2015. p. 65-95.

20. Ginzburg C. Mitos, emblemas, sinais: morfologia e história. São Paulo: Cia. das Letras; 1989.

21. Freire IM. Temática "Responsabilidade social" na literatura da Ciência da Informação indexada pela BRAPCI. In: Anais do $14^{\circ}$ Encontro Nacional de Pesquisa em Ciência da Informação; 2013 out.-nov. 2901; Santa Catarina, Brasil. Florianópolis: UFSC; 2013.

22. Bufrem LS, Costa FDO, Gabriel Junior RF, Pinto JSP. Modelizando práticas para a socialização de informações: a construção de saberes no ensino superior. Perspect Ciênc Inf [Internet]. 2010 [citado em 2019 nov. 23];15(2):22-41. Disponível em: www.scielo.br/pdf/pci/v15n2/a03v15n2.pdf. 